\title{
Unha ollada dende o xénero á emerxencia climática
}

\author{
A gender-look to the climate emergency
}

- Alberto José Franco Barrera

Universidade de Santiago de Compostela, España

\section{NOTAS BIOGRÁFICAS}

Alberto José Franco Barrera é licenciado en Ciencias Políticas e doutor en Filosofía. Actualmente é profesor substituto na Facultade de Humanidades da Universidade de Santiago de Compostela. Traballa dende fai tempo nos vencellos entre democracia e cambioclimático.

Contacto: al bertojose.franco.barrrera@usc.es

$<<$ En canto hai unha crise económica e, por tanto, menos recursos enerxéticos dispoñíbeis; quen sae perdendo sempre de xeito brutal, en calquera país, son as mulleres >>, a sentenza pronunciada por Xabier Vázquez Pumariño, na conversa que mantivo con Manuel Casal Lodeiro para o actual número da RICD, condensa de xeito maxistral a situación global das mulleres tanto na historia recente da humanidade coma no contexto actual. Un contexto marcado polo reto político, económico e social máis importante do século XXI: as alteracións climáticas.

Este fenómeno soe tratarse como un simple exceso de dióxido de carbono nun sistema polo demais pulcro e eficiente; sen embargo, a crise climática non é un problema onde todos sexamos igualmente responsábeis nin sufrimos os seus impactos de xeito indiscriminado. Por contra, o problema está vinculado a numerosas dinámicas de poder e, por conseguinte, afecta a algunhas persoas máis cá outras. Por exemplo, dende unha perspectiva de xénero pódense abordar todos e cada un dos temas tratados na conversa; mais imos limitar esta primeira análise a tres problemas específicos: a pobreza, as migracións e o discurso neoliberal centrado nas accións individuais para combater as alteracións climáticas.

En primeiro lugar, é coñecido dende fai tempo que a emerxencia climática afecta de xeito desproporcionado aos máis pobres; agrava, por tanto, as situacións de desigualdade a nivel internacional e dentro de cada país. As nacións do Sur Global están a ser as máis afectadas por secas, inundacións, malas colleitas, migracións, aumento do nivel do mar e conflitos varios ${ }^{1}$; situacións empeoradas polas historias de colonización e extracción da súa riqueza por parte do Norte Global ${ }^{2}$. Evitando, por outra banda, que estean en posesión dos recursos necesarios para construír a infraestrutura requirida para se recuperar dos desastres anteriormente mencionados.

Neste contexto hai que sinalar que o $70 \%$ das persoas por debaixo do limiar da pobreza son mulleres. Mulleres que son coidadoras primarias do fogar e que teñen que seguir alimentando ás súas familias sen importar que crise sufran; ou en palabras de Vázquez Pumariño $<<$ pequenas unidades enerxéticas que proveen ao resto da comunidade $>$ e, todo isto, dende ocupacións altamente vulnerábeis que non poucas veces son invisíbeis aos programas de recuperación ao non estar consideradas actividades produtivas.

En segundo lugar, dos desastres climáticos xa presentes poucos están tan atravesados pola cuestión de xénero como as migracións: 20 de cada 26 refuxiados climáticos son mulleres ${ }^{3}$. Prevalecendo unha maioría de mulleres novas e menores de idade, potenciando así ás probabilidades de sufrir abusos ou trata ${ }^{4}$. Por outra banda, o xénero non só determina quen está a migrar senón tamén quen pode regresar ás súas comunidades despois dunha catástrofe 5 . Ademais, sexan migracións ou non, ante os desastres climáticos aumenta o risco de violencia de xénero xa que se perden fogares e sistemas de protección e apoio ás mulleres, á infancia, ao 
colectivo LGBT e ás persoas con diversidade funcional6.

Por último, unha cuestión que non ten por costume ser tratada dende a perspectiva de xénero son os discursos neoliberais que fan énfase na acción individual e isto a pesar de que sitúan as responsabilidades da redución de emisións nos actores domésticos e, por tanto, nas mulleres especialmente. Noutras palabras, son os comportamentos e accións de consumo privado das mulleres os cales se examinan máis minuciosamente nos discursos dominantes sobre a mitigación para concluír, segundo certas lóxicas, que un dos xeitos máis eficaces de combater as alteracións climáticas é evitar ter descendencia.

Isto último vencella co fincapé do neoliberalismo na cuestión de limitar a poboación mundial para obter, deste xeito, a sostibilidade ambiental. Vázquez Pumariño e Casal Lodeiro caen neste trampa ao mencionar varias veces durante a súa conversa o perigo de ser uns 7.500 millóns de persoas no planeta. Non é novidoso, sen embargo, que os corpos das mulleres sexan medios para cumprir fins demográficos; tampouco é novidade que algúns destes proxectos pretendían servir a fins sociais incuestionábeis, como a redución da pobreza ou a paz. Agora ben, por que é unha trampa este discurso?

Primeiro, porque dende unha perspectiva de xénero hai que mostrarse escéptica ante os discursos que teñen un apoio total aos dereitos reprodutivos e, ademais, sinalan a feliz coincidencia de que a liberdade das mulleres de pór límites á matemidade sexa tamén unha solución ante as ameazas das alteracións climáticas. A verdadeira xustiza reprodutiva inclúe a opción de elixir cantos fillos ter e crialos nunha contorna segura e saudábel, pero moitos dos que intentan instrumentalizar estes dereitos básicos, non é o caso dos dous protagonistas da conversa, pasan a gran velocidade a defender os beneficios para a redución de emisións que existen cando determinadas mulleres non teñen descendencia? .

Segundo, porque os enfoques que centran a loita contra a emerxencia climática na poboación mundial, sen importar o fundamento político detrás da defensa, están atravesados por dúas grandes falsidades. Unha é que a poboación mundial disparouse nos últimos anos cando a realidade é que o ritmo de crecemento diminúe dende os sesenta; de feito, de 1990 a 2019 a taxa de fecundidade mundial descendeu ${ }^{8}$. A outra é que a principal ameaza á cal nos enfrontamos como sociedade é a escaseza de recursos ${ }^{9}$, cando en realidade o problema está na distribución desigual das necesidades bási$\operatorname{cas}^{10}$ e na dependencia excesiva respecto a ecosistemas fráxiles.

Dúas críticas máis que se lles pode facer a Casal Lodeiro e Vázquez Pumariño xiran arredor do concepto de Antropoceno e do denominado Green New Deal (GND). Por unha banda, parece incríbel que non fagan mención algunha ao Antropoceno ou ao Capitaloceno, xa que co uso do primeiro estarían resaltando o papel das alteracións climáticas como transformación global resultado das accións humanas e con consecuencias diversas en distintos territorios; mentres que co segundo, por contra, farían fincapé nunha proposición para entender as relacións co non-humano nos procesos capitalistas.

Sorprende, sobre todo, o esquecemento de Capitaloceno porque este concepto relaciona mellor cos procesos extractivistas de longa duración que produciron a intensificación da explotación e, por tanto, un aumento das desigualdades entre seres humanos e non-humanos causadas polas concepcións que os diferencian, baseadas na noción binaria de natureza-cultura asociada, por outra banda, a procesos de creación, apropiación e globalización das diferentes naturezas.

Unha outra posibilidade era apostar, como fai o ecofeminismo nos últimos anos, polo termo Chthuluceno11. Un concepto composto por historias e prácticas de convivencia entre múltiples especies; é dicir, os humanos non serían os únicos actores importantes senón que xunto con outros seres compartiría o actual contexto de crise climática e ambiental. Na súa fomulación fai referencia a multitude de sistemas complexos onde se vinculan e complementan distintos suxeitos, temporalidades e espazos. No Chthuluceno crear parentescos é de vital importancia; entendendo este parentesco non como entidades unidas por unha ascendencia senón novos tipos de relacións entre humanos e non-huma$\operatorname{nos}^{12}$.

Por outra banda, non é xusta a crítica ao GND, ao menos a crítica xeral que realizan os dous protagonistas ao concepto. Estando de acordo é que non ten sentido ningún falar de crecemento verde, faise necesario mencionar que non todas as defensas políticas deste modelo concordan en como artellalo, e se ben é certo que existen visións que se poderían englobar dentro do capitalismo verde moitas outras non. Nestas últimas hai discursos que intentan construír ideas dun futuro non dependente dos combustíbeis fósiles, é dicir, existen modelos de GND que integran ideas decrecentistas ${ }^{13}$. 
Dende distintas iniciativas populares de xustiza climática demandan vidas materialmente máis austeras, pero que sexan ao tempo máis seguras e máis plenas. Visións que defenden o programa ecofeminista de desfeminizar os coidados e repartilos igualitariamente entre os membros da comunidade, mais tamén valorándoos simbólica e economicamente e así converténdoos en parte esencial da axenda central de calquera sociedade. En definitiva, non é unha cuestión de evitar as críticas ao GND senón de coñecer cal é a posibilidade real de cambio no contexto actual e que iniciativas temos procurando unha saída.

Dito isto, coincídese plenamente coa visión de Vázquez Pumariño e Casal Lodeiro con relación aos Obxectivos de Desenvolvemento Sostíbel (ODS), pero ademais das contradicións formuladas durante a conversa é necesario sinalar algunha eiva máis. Unha primeira relacionada coa medición lineal de cada un dos obxectivos, feito que complica a análise sistémica dos impactos de calquera deles. Por exemplo, imaxinar que efectos tería unha redución das emisións de dióxido de carbono (punto 13: acción climática) sobre o resto de obxectivos; é dicir, se os indicadores non asignan metas comúns vai ser imposibel coñecer o impacto conxunto da Axenda 2030.

Unha segunda limitación é máis de fondo que de forma, e está relacionada coa total ausencia dos debates éticos do século XXI. Por exemplo, no punto nove (industria, innovación e infraestrutura) non se ten en conta a experiencia dos algoritmos discriminatorios por razón de raza, sexo ou tendencia sexual que afectarían, por nomear un, ao ODS número cinco (igualdade de xénero) ${ }^{14}$. Igualmente queda fóra de toda discusión o papel dos dereitos dos animais na consecución dos devanditos obxectivos.

Cuestión, esta última, que non é intranscendente. Ter algún obxectivo dedicado xa non á chamada liberación animal, senón a unha forte visión do seu benestar axudaría a paliar numerosos problemas medioambientais (puntos 14: vida submarina; punto 15: vida ecosistemas terrestres) e sería un gran paso na loita contra a crise climática e o modelo económico neoliberal que a alimenta ${ }^{15}$. Noutras palabras, o impacto sistémico de engadir un ODS destas características seńa extremadamente beneficioso e sen embargo nin sequera dende algunhas visións decrecentistas está presente.

En calquera caso, como ben comentan Casal Lodeiro e Vázquez Pumariño, o erro fundamental da Axenda 2030 é a inclusión do crecemento económico (punto 8); e se ben é certo que ese concepto ten varias aproximacións críticas que intentan afastalo dos mitos económicos sobre os cales se constrúe na actualidade, a realidade dende as institucións é outra moi distinta. Non se fai a análise material necesaria que explique como o tipo de sociedades das que gozamos no Norte Global dende a Segunda Guerra Mundial, son modelos que se sostiveron sobre un momento mineral excelente e sobre un exército de reprodución xeracional da vida: as mulleres nos fogares.

Faise imprescindỉbel, entón, camiñar cara a un modelo non só economicamente decrecentista senón procurar vías para a construción dunha democracia sen carbono. É necesario que as comunidades e as institucións comecen a se facer cargo da reprodución cotiá da vida e aborden o enquistado poder do capital fósil, así como os danos causados por este ao longo do tempo. A sociedade indispensábel para loitar contra as alteracións climáticas constrúese dende a propia loita e sen esquecer que non todos os movementos democráticos procuran a xustiza climática nin todo movemento ecoloxista vai acompañado de máis democracia. Para concluír, así como os nosos protagonistas advirten de que o colapso non ten unha data concreta, é importante sinalar que as nosas sociedades non están ante a última oportunidade de frear as alteracións climáticas senón ante a última posibilidade de facelo dun xeito xusto para as actuaise, sobre todo, para as vindeiras xeracións.

\section{NOTAS}

1 IPCC (2014). Climate Change 2014: Impacts, adaptation and vulnerability: Key findings and lessons learned. Intergovernmental Panel on Climate Change.

2 Sealey-Huggins, L. (2017, September 11). 3 Ways Inequality is at the Heart of Hurricane Irma's Destruction. Novara Media. https://novaramedia.com/2017/09/11/3ways-inequal ity-is-at-the-heart-of-hu rrica ne-irmas-

destruction/

3 IPCC (2014). Climate Change 2014: Impacts, adaptation and vulnerability: Key findings and lessons learned. Intergovernmental Panel on Climate Change.

4 IOM (2014), Outlook on migration, environment and climate change, International Organization for Migration.

5 Chindarkar, N. (2012). Gender and climate changeinduced migration: proposing a framework for análisis. Environmental Research Letters, (7), 01-07.

6 Lama, P., Hamza, M. \& Wester, M. (2020). Gendered dimensions of migration in relation to climate change. Climate and Development, DOI: 10.1080/17565529.2020.1772708. 
7 Fincapé en determinadas mulleres, é dicir, mulleres racializadas.

8 Lederer, E.M. (2019, June 17). UN: World Population expected to rise to 9.7 billion in 2050. Associated Press https://apnews.com/article/ebb1e955ce444b7ab23febe5a b18dcd1

9 Con esta afirmación non se defende, en ningún caso, que os recursos sexan infinitos.

10 Noutras palabras, a crise ambiental é causada polo aumento da produción e do consumo por habitante e non polo aumento da poboación. Hai que fixarse en quen consume que.

11 Haraway, D. (2015). Anthropocene, Capitalocene, Plantatiocene, Chthulicene: Making Kin. Environmental $\begin{array}{llll}\text { Humanities, } & 6 & \text { (1), } & 159-165 .\end{array}$ https://doi.org/10.1215/22011919-3615934

12 Este concepto, en definitiva, intenta centrarse en dúas características común a todas as especies do planeta: a vulnerabilidade e a conexión necesaria para a subsistencia de todas elas.

13 De feito, ao inicio da conversa Casal Lodeiro e Vázquez Pumariño mencionan varias iniciativas populares, de nova creación, con visións decrecentistas que defenden a idea dun Green New Deal. Por exemplo, unha boa parte da organización Extinction Rebellion ou o Movemento Sunrise.

14 Fernández Mateo, J. (2019). Los Fundamentos Epistemológicos de la Transformación Digital y sus efectos sobre la Agenda 2030 y los Derechos Humanos. Icade: Revista Cuatrimestral de las Facultades de Derecho y Ciencias Económicas y Empresariales, (108). DOI: https://doi.org/10.14422/icade.i108.y2019.004.

150 modelo intensivo e industrial de produción de carne, por exemplo, estaría afectado de incluír un ODS a favor dos dereitos dos animais e, por conseguinte, a forma na cal se alcanzaría o segundo punto dos obxectivos: a fame cero. 